\title{
ON A PARASITIC DROSOPHILA FROM TRINIDAD.
}

\author{
By C. G. Lamb, M.A., B.Sc., \\ Clare College, Cambridge.
}

The material for this paper was forwarded to the author by Dr. Guy Marshall, of the Imperial Bureau of Entomology, and was collected by Mr. C. B. Williams.

The insects were said by him to be parasitic on a Cercopid of the genus Clastoptera, which was found attacking cacao trees. This highly unusual habit gives much interest to the species. Unfortunately the number of individuals sent was quite inadequate to enable one to deal satisfactorily with such small and obscure insects, especially as shrivelling takes place to a different extent in various individuals, which renders the provision of a reasonably large number more necessary than in more normal forms of fly. The individuals sent included three pinned ones of a species from Trinidad (West Indies), and one pinned one of a species from Panama, together with the fragments of two others of the latter species in spirit. In spite of the paucity of material, it was felt to be desirable to put on record as fair a description as could be made under the circumstances. Two of the individuals of the Trinidad species were of one sex, and the third was apparently the other sex of the same species. The two former had all the appearance of representing the male, having

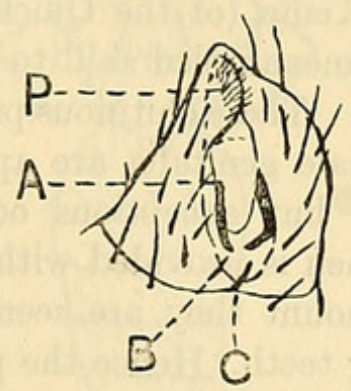

Fig. 1. Terminal segments of Drosophila paradoxa, ${ }^{\text {, }}$ viewed obliquely from below, $\times 70$; explanation in text.

brighter eyes, darkened wings, and the general facies of that sex. The genitalia were small and hidden in a terminal hood, such as is found in Drosophila melanogaster and Leucophenga maculata, but it was smaller than in either of these, even than in the latter, in which the hood is only moderately open at the tip, while widely so in the former. In both these species the genitalia can be seen inside the hood, but in the present species only the tips of the fleshy processes are visible. Still, as far as things can be made out without destroying the specimens, they will pass for males. The desirability of having a few spare individuals available for dissection is very great, as otherwise points of this sort have often to be left in some uncertainty. Very little doubt would have been felt on this matter had it not been for the unusual characters possessed by the third specimen. On the lower surface of the abdomen are borne some truly remarkable chitinous hooks; in fig. 1 is shown a somewhat diagrammatical representation of the terminal segments viewed obliquely from 
beneath. The last segment is large, and is hollowed out in a shallow pocket whose boundary is shown by a dotted line. Towards the tip of the abdomen this pit is bounded by a very hairy elongate papilla $(\mathrm{P})$, which is very like the similar hairy prominences so usual in females of this family. It is well marked and definite, and can be just seen projecting beyond the end of the body when the insect is viewed from above. Inside the shallow pocket lie two very stout sharply bent chitinous rods, each being L-shaped, attached by the longer arm of the $\mathrm{L}$ to the bottom of the pocket $(A)$ with the pointed end $(B)$ of the rod pressing against the ventral surface. Between the rods the floor of the pocket is somewhat arched. Forward of these rods arises a fine sharp chitinous rod, slightly curved, based as at C, with the sharp point projecting backwards. The presence of these appendages causes much difficulty. But for them, the general appearance of the insect, the points in which it differs from the other two, the external form of the abdomen, \&c., are such that one would have had little hesitation in considering it to be the female of the other two specimens. Remarkable chitinous appendages occur in some male Drosophilids ; for example, D. obscura possesses an extraordinary five-branched chitinous appendage projecting forwards from the last segment, and other species seem to possess such structures, though not so highly specialized in form. This process is apparently the penis. Most males show no signs of such external appendages, but it is possible that in such cases they are small and internal, though all that can be seen consists of various complex fleshy processes. The question is one well worthy of investigation, and the author is hopeful that Dr. Keilin (of the Quick Laboratory, Cambridge) may be able to devote a little of his unexampled skill to the elucidation of this point in some of our more common species. These chitinous processes are, as far as one knows, all median and single. The female genitalia are apparently nearly always simple in structure and of soft tissue, but exceptions occur in some cases. Thus, in Scaptomyza graminum the abdomen is provided with two chitinous processes which look like tiny saws, and in a mount they are seen to be truly saw-like external appendages with sharp bordering teeth. Hence the presence in the female of paired chitinous appendages is proved in certain species of the family, and thus the objection to the present insect being a female (owing to their presence) is of less weight. In fact, it is possible that they are homologous with the saws of Scaptomyza, and have been modified in some way to suit the parasitic habits of the present species. The median process is so inserted and so orientated that it is highly improbable that it is a male organ. It might, indeed, be argued that we have before us the males of two different species, but a close and critical comparison was made of the Trinidad specimens, and the agreement in chaetotaxy, venation, and nearly all the external characters is so very close, that nothing warranting such a conclusion is apparent. Hence, for the present, the only thing to do is to consider the two similar individuals of the Trinidad species to be males, and the third to be a highly aberrant type of female of the same species.

It may be as well to add a few words concerning the Panama species, as little can be said later on. The pinned example was rather shrivelled, and so bent as to make critical examination almost impossible, hence it can only be described in a rather superficial manner. As far as outside appearance went, both the pinned and the spirit specimens were females. Hence the latter fragments were given to 
Dr. Keilin, who made a mount of them with especial reference to the genitalia. As far as can be judged, they are fairly typical females, with absolutely no sign of the external appendages found in the first species. There is evidence of paired and unpaired chitinous processes in the mount, but they are all internal. Hence the matter must, for the present, be left in abeyance pending further investigation on several forms.

The description of the Trinidad species is as follows :-

Drosophila paradoxa, sp. nov. (fig. 2).

A minute species, well under $2 \mathrm{~mm}$. in length, exhibiting broadly the usual appearance of the small pale yellow species, except for having darkened wings. The whole insect is pale yellow, including the legs, except for a slight darkening of the ti $\mathrm{p}$ of the abdomen.

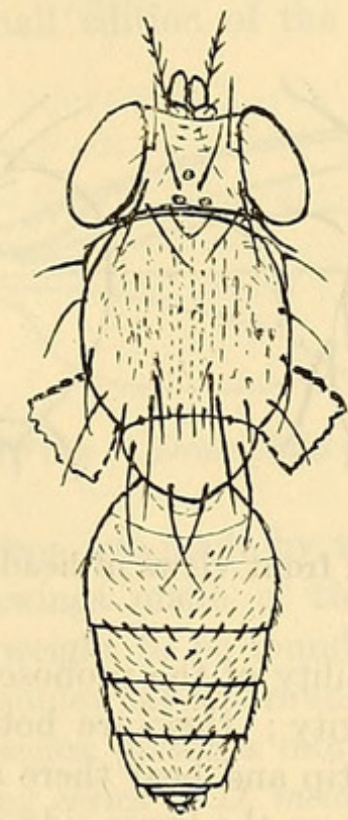

Fig. 2. Drosophila paradoxa, Lamb, sp. n., $\times 30$.

c. Head (fig. 3) : frons all shining, the central triangular area (bounded by the dotted lines in fig. 2) being slightly depressed, with three pairs of small converging hairs on the boundary lines. The chaetotaxy is quite normal, as figured; the small front bristle of the outer f.o. row is just in the same line with the large inner f.o. (the position of this small f.o. bristle is a useful character in the genus). The bristles are all somewhat exceptionally stout and are golden brown in colour; the ocelli are bright red. The eyes are well rounded, as shown in fig. 3 ; under a power of 40 diameters a very sparse and scattered pubescence can be seen. The concave hind head is also entirely yellow. The antennae (fig. 3) have the first joint quite hidden by the lunular ridge; the second joint is globular and has a few bristles, an especially long one at the base, and another towards the front; the third joint is rounded in profile, but somewhat pointed when viewed from in front. It will be seen that the antennae are absolutely approximated at the base, there being no vestige of the facial keel so common in these small yellow species, and indeed the 
face is but slightly arched from eye-margin to eye-margin. The antennal joints are wholly pale yellow. The arista (fig. 3) has four upper rays, a terminal ray and one apical lower ray, but none on the basal part; under a power of 90 diameters one can just see a few of the usual inner row of tiny rays. The arista is bright yellow up to just beyond the insertion of the second upper ray ; the rest, together with all the rays, is black. The mouth vibrissae are single and very strong, and the stout bristles on the jowls (lower and hind) are quite strikingly developed. The buccal opening is somewhat unusual in structure. In the normal Drosophilid mouth, if one looks straight into it from below, one will see the fulcrum in the form of an elongate arch widely separated from the actual mouth-edges by the membranous sides which join it to the same. In the present species the fulcrum follows closely and exactly the mouth-margin, so that its long axis is across the mouth, instead of axial, and in fact there appears to be no room for the membranous connections, and hence
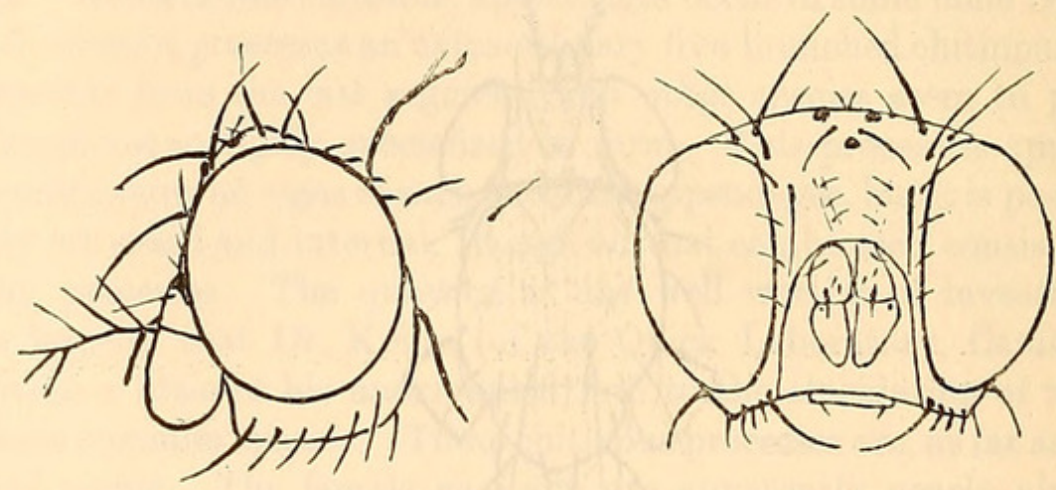

Fig. 3. Lateral and front views of head of D. paradoxa.

little possibility for the usual mobility of the proboscis. The tongue and palpi are inserted deeply in the buccal cavity; they are both entirely pale orange. The palpi are slightly clubbed at the tip and bear there a small black terminal bristle, and there is a single similar bristle on the lower side of the end.

The thoracic dorsum (fig. 2) is also pale, rather shiny yellow, although in certain illuminations two indistinct orange lines can be seen showing through the chitin. The surface is entirely covered with regular rows of tiny bristles, which, as usual, show black against the dorsum but golden on side view; the middle six rows of these bristles (shown as four only in the figure) form the acrostichal rows. Three pairs of post-sutural dorso-centrals are present, the first very small, the next long, and the last very long, extending over the scutellum. There are 4 small prescutellars, and the rest is as shown in the figure. The scutellum is absolutely smooth and of the same yellow colour as the dorsum, as is also the metanotum. The pleura is also all of the same colour ; the large terminal humeral bristle is accompanied by an almost equally large one on the lower side of the humerus and 2 or 3 smaller ones. There are two sternopleural bristles inserted rather closely together, the hind one being very long and stout, the other about half its size.

The legs are likewise entirely pale yellow and are well clothed with tiny bristles; the coxae carry long irregular bristles, and the front femur is provided with a lower row of 6 or 7 stout bristles; there are no special adornments on the front legs. 
The wings have the form and venation shown in fig. 4. The lower cross-vein is broadly clouded as indicated by the dotted lines. A darkened area extends from the costa across to the third vein, the approximate boundary of its darkest part being shown by dots; the darkening then quickly shades off into the greyish glassy surface of the rest of the wing. The basal segment of the costa is well bristled, the last bristle at the costal break being the strongest.

The abdomen is yellow and slightly shining, the last two segments being darkened with ill-defined borders extending broadly along the hind margins of the segments. The dorsum is covered with small bristles somewhat converging towards the axial line; the marginal bristles, about 4 on each side, are considerably longer and stouter and more regularly spaced. The hypopygial segments are somewhat darkened and hairy ; all that is externally visible is a small terminal knob and what are possibly the tips of the side appendages; the whole apparatus gives one the impression of its being a small edition of the type of thing seen in Leucophenga maculata.

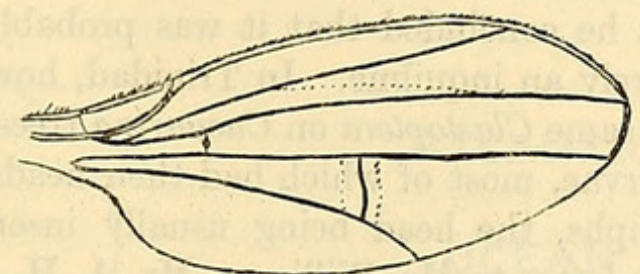

Fig. 4. Wing of Drosophila paradoxa, $\times 30$.

ㅇ. A very careful comparison was made by viewing the specimen in conjunction with the camera lucida drawings made of the male. There is practically no structural difference of any weight to be found. The lower hind quadrant of the eye boundary in side view is somewhat less rounded, but that is a matter that varies to some extent in a single species, giving a more or less pointed appearance to the lower part of the eye. A long series of $D$. melanogaster will show quite perceptible differences in this respect. The chaetotaxy, both cephalic and thoracic, and the relative size of the bristles are the same, as are the legs. The wings have exactly the same venation and relative positions of all the veins, but are very slightly shorter. The main difference is in the colour of the wings; the suffusion is almost absent, but can just be seen in a proper light. The peculiar structure of the abdomen has been described on p.157. The central hairy ridge is pale yellow on its base. The last segments are more darkened, and the terminal one bears a crown of regularly spaced bordering bristles, which are stout and very nearly as long as the previous segment.

Length, just under $2 \mathrm{~mm}$; wing, the same.

Trinidad : St. Joseph, 3 specimens, xii. 1917 (C. B. Williams).

The single female from Panama is superficially very like that of the last species. The side view of the head is much the same, but it is not quite so high in proportion to its breadth, and the jowls are a little narrower. The inner row of aristal rays is very evident. The thorax was spoiled in pinning, but as far as can be seen the chaetotaxy is the same, as is that of the head, though the bristles are less stout. 
The venation is different: on micrometric measurement it is found that the ratio distance from small to large cross-vein distance from large cross-vein to wing-margin $=0.42$, while in $D$. paradoxa it is about 0.62 ; also as measured along the costa we have $\frac{\text { end of } 1 \text { to end of } 2}{\text { end of } 2 \text { to end of } 3}=1 \cdot 6$, whereas in $D$. paradoxa it is a little over 2 ; hence the 2 nd vein is proportionally much shorter. The free end of the 5th vein is also longer, and there is no darkening at all of the veins or costal border.

The pinned specimen was so badly placed for viewing that the abdomen could not be properly examined, but it was apparently very like that of the last species externally. The fragmentary specimens were mounted as slides, as before mentioned, and hence are not much help in description.

Size, as last species.

Panama: Changunda, xi, 1917, (C. B. Williams).

[In a later communication Mr. C. B. Williams states that from what he saw of the Panama Drosophila he concluded that it was probably not a true parasite of the Clastoptera, but merely an inquiline. In Trinidad, however, he collected about 30 spittle-masses of the same Clastoptera on Casuarina trees, and about half of these contained Drosophila larvae, most of which had their heads buried in the abdomen of the Clastoptera nymphs, the head being usually inserted between the dorsal abdominal plates. In a letter to Mr. Williams, Mr. A. H. Sturtevant, of Columbia University, New York, says: "Similar habits have been observed in Drosophila inversa, Walker, in Minnesota. C. N. Ainslie (Canad. Ent. 1916, pp. 38-44) reported this species (incorrectly determined as $D$. sigmoides, Loew) as bred from pupae found in the froth of a Cercopid."-ED.]. 


\section{$2 \mathrm{BHL}$ Biodiversity Heritage Library}

1918. "On a parasitic Drosophila from Trinidad." Bulletin of entomological research 9, 157-162. https://doi.org/10.1017/S0007485300037895.

View This Item Online: https://www.biodiversitylibrary.org/item/110215

DOI: https://doi.org/10.1017/S0007485300037895

Permalink: https://www.biodiversitylibrary.org/partpdf/49399

\section{Holding Institution}

Smithsonian Libraries

\section{Sponsored by}

Biodiversity Heritage Library

\section{Copyright \& Reuse}

Copyright Status: Public domain. The BHL considers that this work is no longer under copyright protection.

This document was created from content at the Biodiversity Heritage Library, the world's largest open access digital library for biodiversity literature and archives. Visit BHL at https://www.biodiversitylibrary.org. 